\title{
Policies for an EU smarter grid environment: A Delphi study on DSOs
}

\author{
Guillermo Ivan Pereira \\ INESC Coimbra - MIT Portugal \\ University of Coimbra \\ Coimbra, Portugal \\ gpereira@student.dem.uc.pt
}

\author{
Patricia Pereira da Silva \\ INESC Coimbra - CeBER \\ University of Coimbra \\ Coimbra, Portugal \\ patsilva@fe.uc.pt
}

\author{
Deborah Soule \\ MIT Initiative on the Digital Economy \\ MIT Sloan School of Management \\ Cambrige, MA, USA \\ dsoule@mit.edu
}

\begin{abstract}
The transition of the European Union (EU) electricity sector toward a smart grid environment has led to uncertainty about the role of distribution system operators (DSOs). This uncertainty is due to the rapid emergence of new service possibilities enabled by new information and communication technologies for electricity management and new distributed energy resources. This research addresses the observed uncertainty through a foresight study in which policy alternatives were evaluated in terms of business model innovation, technological adaptation, and market design issues. For this purpose, 208 experts evaluated 57 policy alternatives, following a Policy Delphi method. The study results indicate the importance of adapting the current business model and the need to simultaneously develop regulatory frameworks that support innovation. The results point to a lack of consensus regarding the degree of technology development and R\&D activity considered appropriate for DSOs.
\end{abstract}

Index Terms-- Smart grids, European Union, DSOs, Policy.

\section{INTRODUCTION}

The ongoing energy transition is driving a shift toward a smarter and more sustainable electricity sector. For electricity distribution system operators (DSOs), this represents new possibilities for service provision resulting from increased levels of automation and monitoring, as well as from the growth of electricity storage solutions, electric vehicles, smart meters, small scale distributed generation and appliances automation [1]. These new services include flexibility facilitation and coordination, energy efficiency promotion, growing data access, deployment of smart meters and facilitation of electric vehicle infrastructure [2]-[4]. DSOs are at the centre of this evolution of the electricity system. On the one hand, they must ensure that their natural monopoly electricity distribution activities continue to be run in a costeffective manner. On the other hand, they must contribute to innovation in the sector, which may require the introduction of new technologies and processes. Importantly, the ability of DSOs to adapt to new roles will affect not only their operations but also the evolution of the system downstream and upstream.

In the context of the European Union (EU) electricity market, DSO responsibilities have been shaped by successive implementations of electricity sector policy packages. This situation can be considered as a two-staged market restructuring process. In the first stage, policy actions were taken to deliver on the ambition of a liberalized electricity market, and implemented through Directives 96/92/EC, 2003/54/EC e 2009/72/EC [5]-[7]. These policies forced a shift from a vertically integrated electricity industry toward more competitive markets for generation and retail, in combination with natural monopolies for network operations. Through this process, DSOs were separated (i.e.: unbundled) from the vertically integrated utilities (VIU). National Regulatory Agencies (NRAs) were created to facilitate and enforce neutral markets. In the second stage, policy actions target the ambition of a smarter and clean electricity sector, through initiatives such as the Energy Union [8], the Digital Single Market strategy [9], and the more recent Clean Energy for All Europeans policy package [10]. These initiatives introduced a set of policy recommendations for shaping the electricity market. They include specific proposals for how DSOs should or could be involved in innovative business activities and the delivery of new services associated with a smarter grid framework [11]. The evolution of DSO responsibilities throughout the different stages of EU market restructuring is presented in Fig. 1.

The authors acknowledge the Portuguese National Foundation for Science and Technology (FCT) for supporting this work through the Doctoral Grant $\mathrm{PD} / \mathrm{BD} / 105841 / 2014$, awarded on the framework of the MIT Portugal Program funded through the POPH/FSE. Additionally, this work has been partially supported by FCT under project grants: UID/MULTI/00308/2013, and SAICTPAC/0004/2015-POCI-01-0145-FEDER-016434, as well as by the Energy for Sustainability Initiative of the University of Coimbra. 


\begin{tabular}{|c|c|c|c|c|c|}
\hline \multirow{3}{*}{ Stage } & \multicolumn{3}{|c|}{ Liberalized electricity market } & \multicolumn{2}{|c|}{ Smart and clean electricity sector } \\
\hline & & & & & \\
\hline & 1996 & 2003 & 2009 & 2015 & 2016 \\
\hline $\begin{array}{l}\text { Policy } \\
\text { Actions }\end{array}$ & Directive 96/92/EC & Directive 2003/54/EC & Directive 2009/72/EC & Energy Union & $\begin{array}{l}\text { Clean Energy for } \\
\text { All Europeans }\end{array}$ \\
\hline $\begin{array}{c}\text { DSO } \\
\text { Responsibilities }\end{array}$ & $\begin{array}{l}\text {-Operation, maintenance, } \\
\text { and development of the } \\
\text { electricity distribution } \\
\text { grid; } \\
\text {-Secure, reliable, and } \\
\text { efficient service provision; } \\
\text {-Neutral market } \\
\text { facilitation; } \\
\text {-Prioritised dispatching of } \\
\text { renewable, waste and } \\
\text { combined heat and power } \\
\text { generation units; } \\
\text {-Preserve the } \\
\text { confidentiality of } \\
\text { commercially sensitive } \\
\text { data. }\end{array}$ & $\begin{array}{l}\text {-Provide users with data } \\
\text { for efficient access and } \\
\text { use of the system; } \\
\text {-Procure electricity to } \\
\text { cover system losses and } \\
\text { reserve capacity in a } \\
\text { transparent way; } \\
\text {-Perform system } \\
\text { balancing in a transparent } \\
\text { way; } \\
\text {-Consider energy } \\
\text { efficiency, demand-side- } \\
\text { management and } \\
\text { distributed generation } \\
\text { when planning } \\
\text { distribution network } \\
\text { developments. }\end{array}$ & $\begin{array}{l}\text {-Modernisation of } \\
\text { distribution grids through } \\
\text { smart grids. }\end{array}$ & $\begin{array}{l}\text {-Procure non-fre } \\
\text { services in a tran } \\
\text { discriminatory w } \\
\text { market participa } \\
\text {-Procure flexibili } \\
\text { improve distribu } \\
\text { operation and d } \\
\text {-Develop electric } \\
\text { infrastructure wl } \\
\text { manifest interes } \\
\text {-Provide non-dis } \\
\text { data through a t } \\
\text { management mc } \\
\text {-Own, develop, } \mathrm{r} \\
\text { electricity storag } \\
\text { parties manifest }\end{array}$ & $\begin{array}{l}\text { ncy ancillary } \\
\text { rent and non- } \\
\text { considering all } \\
\text { ervices to } \\
\text { system } \\
\text { lopment; } \\
\text { hicle charging } \\
\text { no other parties } \\
\text { ninatory access to } \\
\text { sparent } \\
\text { I. } \\
\text { lage, or operate } \\
\text { hen no other } \\
\text { erest. }\end{array}$ \\
\hline
\end{tabular}

Figure 2. DSOs and the EU electricity market restructuring stages. Data from: [5], [6], [10], [11], [20]

The ongoing transition, associated with the evolution toward a smarter grid framework, has raised concerns about how DSOs should position themselves. These concerns recognize the potential for conflict between the natural monopoly characteristics of electricity distribution network activities, and the responsibilities resulting from the diffusion of smart grid innovations, which may be associated with activities to be developed in competitive markets [2], [12].

In this research, we define a smarter grid environment as comprising advances on two fronts: 1) the integration of information and communication technologies (ICTs) to facilitate distribution network activities, and 2) the integration of distributed energy resource technologies such as electric vehicles and necessary charging infrastructure, distributed generation technologies, electricity storage technologies, and smart metering equipment. Collectively, these changes create uncertainty about appropriate roles for DSOs in the future of the EU electricity market, as well as uncertainty about appropriate market designs for these possible new services. This uncertainty for DSOs is heightened by the complexities of their regulated activities, legacy technological assets, and a business model focused on grid planning, expansion, operation, and maintenance.

Additionally, any DSO transition encompasses multiple dimensions: the institutional dimension, related to the policy framework under which DSOs must operate and adapt; the technological dimension, related to the introduction of innovative technologies and resulting impact for network operations; and the organisational dimension, which includes the firm-level capabilities of DSOs to adapt their business model and strategy in response to the institutional and technological dynamics [13], [14].

Through this research, we aim to reduce this uncertainty by presenting a foresight study on the changes affecting DSOs. We were guided by the following research question: What are the most adequate electricity sector policy and market design characteristics for DSOs operating in a smarter grid environment? A Policy Delphi method was applied to develop a more detailed understanding of the policy alternatives associated with the transition towards a smarter electricity sector in the EU.

The paper is structured as follows: the methodology section describes the Policy Delphi and its implementation for this research; the results section describes a sample of the collected data, the discussion section provides a complementary perspective based on both the existing policy framework and the current data. Finally, the conclusions and policy implications section explores the possible impacts of this research for policy makers.

\section{MethODOLOGY}

The Policy Delphi method applied in this research is part of the group of Delphi techniques, which are typically used to gain insight into topics marked by uncertainty and for which knowledge from experts is accessible [15]. This method involves iterative steps through which experts' knowledge is collected and analysed. It aims for greater stability in responses across iterations, to inform and reduce the complexity associated with the subject of analysis. Notably, this method does not seek consensus. Instead, it aims for stability in responses from participating experts, which does not necessarily imply consensus among those experts [16].

The Policy Delphi applied in this research also follows an iterative process. Used as a tool for policy foresight, this method enables the generation of policy alternatives, where diverging opinions highlight the selection of options policy makers should consider [17], [18]. This is particularly valuable as it enables the exploration of policy and market design options for DSOs by testing different scenarios and future hypotheses [19].

The implementation of the Policy Delphi consisted of the following steps:

- Literature review: scientific and policy documents were reviewed to identify relevant areas of analysis. 
- Industry insight collection: semi-structured interviews were conducted with three DSOs of varying size and a NRA representative. Open-ended questions yielded new knowledge that complemented the literature review.

- Policy Delphi participants' selection: invited experts were selected based on the following criteria: affiliation in entities working at the intersection of smart grids development and EU electricity market design; interest in future policies for the EU electricity sector; and willingness to collaborate in a foresight study for analysing policy issues at the DSO level.

- Policy Delphi Questionnaire development: a questionnaire was developed based on input from the literature review and industry interviews. It focused on three areas: business model innovation, technological adaptation, and policy development.

- Policy Delphi Questionnaire piloting and validation: the initial version of the questionnaire was distributed to a group of six experts: two from industry, representing DSOs, and four from academia, representing knowledge in electricity markets, energy policies, and organisational adaptation.

\section{RESULTS}

The Policy Delphi instrument was distributed to 1357 experts for the $1^{\text {st }}$ round of data collection. Of these, 243 responded to the study, while 208 provided a complete questionnaire, yielding an $85.6 \%$ response rate. The study was conducted between December, 2016 and February, 2017. The experts represented 27 countries as follows: Austria (7.5\%), Belgium (3.2\%), Bosnia and Herzegovina (0.5\%), Bulgaria $(0.5 \%)$, Croatia (2.1\%), Cyprus (1.1\%), Czech Republic $(1.6 \%)$, Denmark $(0.5 \%)$, Finland $(4.3 \%)$, France $(3.2 \%)$, Germany $(8.0 \%)$, Greece $(2.7 \%)$, Ireland (1.6\%), Italy $(10.7 \%)$, Latvia $(0.5 \%)$, Netherlands $(7.0 \%)$, Northern Ireland (1.1\%), Norway (2.7\%), Portugal (20.9\%), Romania (0.5\%), Slovenia (1.1\%), Spain (4.8\%), Sweden (6.4\%), Switzerland (1.6\%), Turkey (1.1\%), and United Kingdom (4.8\%). The 208 responses included in the analysis spanned the following stakeholder categories: Distribution System Operator (40.9\%), Electricity Generation Companies (4.3\%), Electricity Retail Companies (1.4\%), Electricity sector associations (1.4\%), Industry analysts and Consultants (13.5\%), Policy Maker (1.0\%), Regulator (1.4\%), Researchers and Academics (27.4\%), Transmission System Operator (2.9\%), and Other $(5.8 \%)$.The final questionnaire included a set of 57 statements concerning business model innovation, technological adaptation, and policy and market design. We included this range of topics with the goal of obtaining a broad perspective, in terms of agreement, importance, and priority.

\section{A. General outcomes}

The following Table I presents the policy issues with high levels of consensus on agreement or importance.

\begin{tabular}{|c|c|}
\hline \multicolumn{2}{|l|}{ Area: Business Model Innovation } \\
\hline $\begin{array}{l}\text { How should DSOs position themselves regarding business } \\
\text { model and organizational innovation? }\end{array}$ & Agree \\
\hline $\begin{array}{l}\text { DSOs should focus on adapting their organisational structure } \\
\text { to be ready for the opportunities resulting from a fully } \\
\text { deployed smart grid }\end{array}$ & $93.8 \%$ \\
\hline $\begin{array}{l}\text { DSOs should provide innovative system services allowing for } \\
\text { new sources of revenue. }\end{array}$ & $86.5 \%$ \\
\hline $\begin{array}{l}\text { DSOs should test strategies that challenge the current } \\
\text { regulation and disrupt the market }\end{array}$ & $70.2 \%$ \\
\hline $\begin{array}{l}\text { In the future DSOs, should be involved in the following } \\
\text { activities? }\end{array}$ & Agree \\
\hline Grid planning (i.e. expansion and reinforcement). & $98.1 \%$ \\
\hline Grid management (i.e. operation and maintenance). & $97.1 \%$ \\
\hline Integration of distributed generation technologies. & $88.9 \%$ \\
\hline Smart meter deployment. & $88.5 \%$ \\
\hline \multicolumn{2}{|l|}{ Area: Technological Adaptation } \\
\hline How should DSOs develop R\&D activities? & Agree \\
\hline $\begin{array}{l}\text { DSOs should explore technological innovation with } \\
\text { universities, ICT firms, and other DSOs. }\end{array}$ & $97.1 \%$ \\
\hline $\begin{array}{l}\text { What is the importance of the following digital capabilities } \\
\text { for DSOs new roles? }\end{array}$ & Important \\
\hline $\begin{array}{l}\text { Collection of data (e.g. from all the connected distribution } \\
\text { networks and devices, such as distributed generation, smart } \\
\text { meters, electric vehicle infrastructure, network monitoring } \\
\text { points, etc.) }\end{array}$ & $93.3 \%$ \\
\hline $\begin{array}{l}\text { Aggregation of data (e.g. from a diversity of sources to obtain } \\
\text { meaningful decision-support information). }\end{array}$ & $91.3 \%$ \\
\hline $\begin{array}{l}\text { Validation and quality certification of data (i.e. to ensure } \\
\text { accuracy and validity of collected information). }\end{array}$ & $90.9 \%$ \\
\hline \multicolumn{2}{|l|}{ Area: Market Design } \\
\hline $\begin{array}{l}\text { How important are the following policy-oriented actions in } \\
\text { the ongoing DSOs transition? }\end{array}$ & Important \\
\hline $\begin{array}{l}\text { DSOs regulation should be designed to facilitate innovation } \\
\text { and investments in smart grid technologies. }\end{array}$ & $94.2 \%$ \\
\hline $\begin{array}{l}\text { DSOs should follow a common-vision of their most effective } \\
\text { role in the electricity value chain, to support and strengthen } \\
\text { the development of the EU internal electricity market. }\end{array}$ & $83.7 \%$ \\
\hline $\begin{array}{l}\text { Member States should develop a National Smart Grid Action } \\
\text { Plan to provide a deployment roadmap and the roles of actors. }\end{array}$ & $79.8 \%$ \\
\hline $\begin{array}{l}\text { A flexibility market governance model should be defined for } \\
\text { the adequate participation of different actors. }\end{array}$ & $78.8 \%$ \\
\hline
\end{tabular}

TABLE I. POLICY ISSUES EXHIBITING HIGH LEVELS OF CONSENSUS ON AGREEMENT/IMPORTANCE.

In terms of business model innovation, experts strongly agreed on the importance of adapting the organisational structure to explore the opportunities of a smarter grid environment (93.8\%). This input is complemented by their perspective on appropriate activities for DSOs. Experts agreed on the role for DSOs in ensuring the delivery of the core electricity distribution network activities, such as grid planning and management. In addition, they agreed that DSOs should be involved in integrating distributed generation technologies, deploying smart meters, and further evolving data gathering capabilities. 
For technological adaptation, most experts agreed on the importance of collaborative R\&D (97.1\%). They also agreed on the importance of digital capabilities like data collection, aggregation, and validation for DSOs. On market design, the experts agreed on the need for innovation supportive regulation (94.2\%) and the need for a common vision for DSOs future roles $(83.7 \%)$.

The data presented in Table II provides a complementary perspective on policy issues. It highlights policy issues with high levels of consensus but on disagreement or low importance.

\begin{tabular}{|l|c|}
\hline \multicolumn{2}{|c|}{ Area: Business Model Innovation } \\
\hline $\begin{array}{l}\text { How should DSOs position themselves regarding } \\
\text { business model and organizational innovation? }\end{array}$ & Disagree \\
\hline $\begin{array}{l}\text { DSOs should focus only on grid operation and } \\
\text { maintenance, planning and expansion, and quality of } \\
\text { service. }\end{array}$ & $70.2 \%$ \\
\hline $\begin{array}{l}\text { DSOs should limit their business strategy to the } \\
\text { possibilities allowed by existing regulations. }\end{array}$ & $67.3 \%$ \\
\hline $\begin{array}{l}\text { How do you perceive the difficulty of DSOs adaptation } \\
\text { to a changing electricity sector? }\end{array}$ & Difficult \\
\hline DSOs will be able to adapt their role in a timely manner. & $65.9 \%$ \\
\hline $\begin{array}{l}\text { DSOs will be able to integrate new technologies to support } \\
\text { the transition to smarter distribution grids. }\end{array}$ & $51.4 \%$ \\
\hline $\begin{array}{l}\text { In the future DSOs should be involved in the following } \\
\text { activities? }\end{array}$ & Disagree \\
\hline Electricity retail. & $59.6 \%$ \\
\hline Electric vehicle infrastructure ownership. & $28.8 \%$ \\
\hline \multicolumn{2}{|c|}{ Area: Design } \\
\hline $\begin{array}{l}\text { How important are the following policy-oriented } \\
\text { actions in the ongoing DSOs transition? }\end{array}$ & $\begin{array}{c}\text { Not } \\
\text { The role of the DSOs should only be specified at the } \\
\text { Member State level. }\end{array}$ \\
\hline $\begin{array}{l}\text { A new regulatory body should be established focusing on } \\
\text { the transition to a smarter grid framework, with a strategy } \\
\text { and incentives for DSOs to innovate. }\end{array}$ & $27.4 \%$ \\
\hline What's the future of DSOs in the electricity sector? & Disagree \\
\hline $\begin{array}{l}\text { DSOs will continue with their traditional activities, solving } \\
\text { most of the grid related issues at the planning stage, } \\
\text { operating as passive network managers. }\end{array}$ & $55.8 \%$ \\
\hline
\end{tabular}

TABLE II. POLICY ISSUES EXHIBITNG HIGH LEVELS OF CONSENSUS ON DISAGREEMENT/LOW-IMPORTANCE.

Regarding business model innovation, most experts disagreed that DSOs should stay limited to their current core activities (70.2\%). They also signalled collective disagreement with DSO strategy being limited by any current regulations $(67.3 \%)$. As for the challenges facing DSOs, many experts saw difficulties for DSOs in adapting their role in a timely manner $(65.9 \%)$ and in adapting new technologies $(51.4 \%)$. In terms of DSO activities, a large proportion of experts believed that DSOs should not be involved in electricity retail $(59.6 \%)$. Considering market design options, many experts disagreed that DSO roles should be defined only at the Member State level $(41.8 \%)$. This perspective complements the strong agreement on the importance of developing and following a common vision, as shown in Table I. Experts also placed low importance on the need for a regulatory body dedicated to the electricity distribution segment $(27.4 \%)$.

\section{B. Technological adaptation}

Since DSO electricity distribution activities are highly regulated, it is important to consider different alternatives for their technological adaptation. We prompted the Delphi experts to consider three technology adaptation alternatives, associated with different levels of risk. The results presented in Table III provide expert insight about how DSOs should prioritize technology development in the course of their adaptation to a smarter grid environment.

\begin{tabular}{|c|c|c|}
\hline $\begin{array}{l}\text { Level of technological } \\
\text { development }\end{array}$ & $\begin{array}{c}\text { DSO Technology adaptation } \\
\text { alternatives }\end{array}$ & $\begin{array}{l}\text { Main } \\
\text { Priority }\end{array}$ \\
\hline $\begin{array}{l}\text { Basic Technology } \\
\text { Research }\end{array}$ & \multirow{2}{*}{$\begin{array}{l}\text { DSOs should conduct exploratory } \\
\text { R\&D activities for new } \\
\text { technologies and innovative } \\
\text { applications. }\end{array}$} & \multirow{2}{*}{$26.4 \%$} \\
\hline $\begin{array}{l}\text { Research to Prove } \\
\text { Feasibility }\end{array}$ & & \\
\hline Technology Development & \multirow{2}{*}{$\begin{array}{l}\text { DSOs should pilot and } \\
\text { demonstrate the potential and } \\
\text { impact of emerging technologies. }\end{array}$} & \multirow{2}{*}{$38.5 \%$} \\
\hline Technology Demonstration & & \\
\hline System Commissioning & \multirow{2}{*}{$\begin{array}{l}\text { DSOs should exploit proven } \\
\text { technologies, deploying external } \\
\text { R\&D results from universities, } \\
\text { ICT firms, and other DSOs. }\end{array}$} & \multirow[b]{2}{*}{$37.0 \%$} \\
\hline System Operations & & \\
\hline
\end{tabular}

TABLE III. TECHNOLOGICAL ADAPTATION ALTERNATIVES FOR DSOS.

The data do not highlight any particular approach: $26.4 \%$ of experts prioritized exploratory R\&D; $38.5 \%$ prioritized piloting and demonstration; while $37.0 \%$ placed priority on DSO exploitation of proven technologies.

\section{Market evolution}

In addition to exploring policy alternatives, the study also analysed market evolution trajectories. Experts were asked to consider a range of future scenarios regarding the timeframe of transition of DSOs from a Passive Network Manager (PNM) into an Active Network Manager (ANM) role. Passive network management describes the situation in which DSOs continue with their traditional activities, solving most of the grid related issues at the planning stage. Active network management describes the situation wherein DSOs incorporate smart grid capabilities, managing system flexibility as part of their operations [2], [13]. Experts considered the likelihood and pace of this role change for both small DSOs and large DSOs. The distribution of their predictions is presented in Fig. 2.

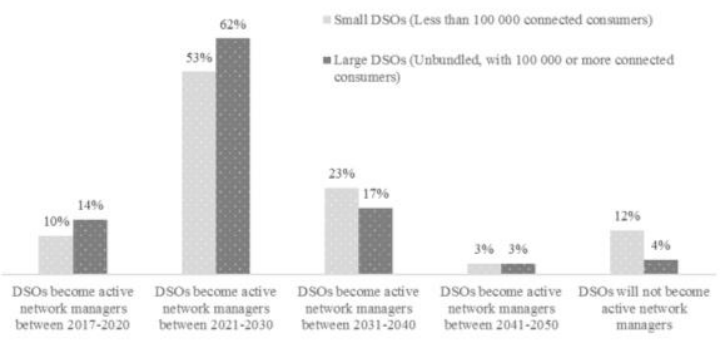

Figure 2. DSO market evolution trajectories.

Fig. 2 shows that most experts believe that both small and large DSOs will shift from PNM to ANM operations between 2021 and 2030 (53\% and 62\% agreement respectively). In the transition from PNM to ANM, there are no significant differences associated with the size of DSO. However, the size of DSO is associated with whether experts believe they will 
transition to Active Network Managers at all: 12\% foresaw that small DSOs will not become ANMs, while only $4 \%$ perceived this outcome for large DSOs.

\section{DISCUSSION}

The results obtained provide indications on the possible characteristics of policies for an EU smarter grid environment for electricity distribution. From the business model innovation policy alternatives, as a proxy for aspects associated with the organisational dimension of DSOs transition, it is possible to signal the relevance of evolving existing organisational structures, as well as of introducing innovative services at the distribution level. This can be acknowledged as a need for DSOs adaptation, which according to the collected data should not be constrained by existing policies and regulations, for testing new operational strategies. These findings highlight the relevance of experimenting with technologies, processes, or practices at the distribution level, which can eventually contribute to a new configuration of electricity distribution operations.

From the technology adoption policy alternatives, as a proxy for aspects associated with the technological dimension of DSOs transition, it is possible to observe the importance of developing research and development in a collaborative environment. However, there is no clear indication about the level of technological maturity for which DSOs should be dedicating their resources. Considering the different risks across maturity stages, it can become valuable to incentivise more engagement in a specific level, such as exploratory research and development, piloting and testing, or exploitation and deployment of proven technologies.

From the market design policy alternatives, as a proxy for aspects associated with the institutional dimension of DSOs transition, the obtained data reinforce the results observed in the business model innovation issues. In this context, the need for a policy and regulatory framework that supports innovation is emphasised. In addition, importance is given to aspects related to governance concerns. The data enhances the relevance of a common-vision for DSOs across the EU, as well as the importance of developing National Smart Grid Action Plans. These two aspects can ultimately be acknowledged as mutually reinforcing, as the common vision at the EU-level can benefit from a detailed understanding of each Member State situations.

\section{CONCLUSIONS AND POLICY IMPLICATIONS}

This research applied a Policy Delphi method to identify the most appropriate policy characteristics for DSOs operating in an EU smarter grid environment. The analysis drew on data collected in cooperation with 208 experts. The results provide foresight indicators regarding business model innovation, technological adaptation, and market design. In terms of business model innovation, the importance of facilitating the adaptation of organisational structures is highlighted, as is the need for DSOs to balance their traditional distribution activities with those related to the integration of distributed energy resources technologies. For technological adaptation, the relevance of pursuing collaborative $R \& D$ endeavours was highlighted, as well as the importance of digital capabilities for data collection, aggregation, and validation in a context of growing data generation by the electricity sector. As for market design, the importance of innovation-friendly regulation is emphasized, in parallel with the need for a shared EU-level vision regarding DSO responsibilities.

These indicators, cover a wide range of institutional, technological, and organisational dimensions, and provide guidance for policy makers working on EU electricity sector market design. Considering this, policy makers attention could focus on balancing the evolving nature of the organisational, technological, and institutional dynamics, for which policy making possibilities include:

- The development of a common-vision for DSOs across the EU by obtaining a detailed understanding of the existing technologies, processes, and practices.

- The development of Smart Grid Action Plans, which similarly to existing Energy Efficiency Action Plans or Renewable Energy Action Plans, could contribute for Member State commitment to deploy smart grids, by focusing on the expected benefits.

- The development of a smart grid governance model, which could contribute with guidance in terms of responsibilities and opportunities for different stakeholders.

Additionally, the relevance of incentivising the engagement of DSOs in specific levels of research and development activities could be considered, given the natural monopoly characteristics of electricity distribution, which can indicate a greater aptitude for research and development that entails less risks for the sustainability of operations. This can be considered in combination with the importance of developing research and development in a collaborative setting, in which the risks can be distributed through the participating stakeholders.

These policy related possibilities can be acknowledged as the need for establishing a framework in which new alternatives can be tested to understand resulting benefits and costs from evolving towards a smarter electricity sector in the EU. This policy implications gain further relevance considering the recent Clean Energy for All Europeans policy package proposals, concerning the role of DSOs in the electricity sector.

Future work includes additional rounds of data collection, following the Policy Delphi methodology, to test the stability of expert assessments after receiving feedback from previous rounds. These further iterations should increase the robustness of the results and yield higher quality indicators for informing the future design of the EU electricity sector market. 


\section{REFERENCES}

[1] P. Mallet, P.-O. Granström, P. Hallberg, G. Lorenz, and P. Mandatova, "European Perspectives on the Future of Electric Distribution," IEEE Power Energy Mag., no. February, pp. 51-64, 2014.

[2] P. van den Oosterkamp, P. Koutstaal, A. van der Welle, J. de Joode, J. Lenstra, K. van Hussen, and R. Haffner, "The role of DSOs in a Smart Grid environment," Amsterdam, 2014.

[3] C. Gellings, M. Samotyj, and B. Howe, "The future's smart delivery system," IEEE Power Energy Mag., vol. 2, no. 5, pp. 40-48, 2004.

[4] C. W. Gellings and R. J. Lordan, "The Power Delivery System of the Future," Electr. J., vol. 17, no. 1, pp. 70-80, Jan. 2004.

[5] European Union, "Directive 96/92/EC of The European Parliament and of the Council of 19 December 1996 concerning common rules for the internal market in electricity," 1996.

[6] European Union, DIRECTIVE 2003/54/EC OF THE EUROPEAN PARLIAMENT AND OF THE COUNCIL of 26 June 2003 concerning common rules for the internal market in electricity and repealing Directive 96/92/EC THE. 2003.

[7] European Union, Directive 2009/72/EC of the European Parliament and of the Council of 13 July 2009 concerning common rules for the internal market in electricity and repealing Directive 2003/54/EC. 2009.

[8] European Commission, "Energy Union Package," Brussels, 2015.

[9] European Commission, "A Digital Single Market Strategy for Europe," Brussels, 2015.

[10] European Commission, "Clean Energy for All Europeans," Brussels, 2016.

[11] European Commission, "Proposal for a Directive of the European Parliament and of the Council on common rules for the internal market in electricity," Brussels, 2016.

[12] L. Meeus and S. Hadush, "The emerging regulatory practice for new businesses related to distribution grids," no. 2016/02, pp. 1-6, 2016.

[13] G. I. Pereira and P. P. da Silva, "Determinants of change in electricity distribution system operators - a review and survey," in 2016 13th International Conference on the European Energy Market (EEM), 2016, pp. $1-5$.

[14] J. Markard, "Transformation of Infrastructures: Sector Characteristics and Implications for Fundamental Change," J. Infrastruct. Syst., vol. 17, no. 3, pp. 107-117, Sep. 2011.

[15] H. Linstone and M. Turoff, The Delphi Method - Techniques and Applications. Addison-Wesley Educational Publishers Inc, 2002.

[16] H. Linstone and M. Turoff, "Delphi: A brief look backward and forward," Technol. Forecast. Soc. Change, vol. 78, no. 9, pp. 17121719, Nov. 2011.

[17] S. Hanafin, "Review of literature on the Delphi Technique," Dublin Natl. Child. Off., 2004.

[18] M. Makkonen, T. Hujala, and J. Uusivuori, "Policy experts' propensity to change their opinion along Delphi rounds," Technol. Forecast. Soc. Change, vol. 109, pp. 61-68, Aug. 2016.

[19] M. McGeoch, K. Brown, and Y. Brunetto, "Policy Delphi: Contribution to infrastrucutre and engineering asset management organizations," in Proceedings of the 7th World Congress on Engineering Asset Management (WCEAM 2012), W. Leoo, B. Choi, L. Ma, and J. Mathew, Eds. Springer, 2012, pp. 459-471.

[20] European Union, Directive of 2009/72/EC of the European Parliament and of the Council of 13 July 2009 Concerning Common Rules for the Internal Market in Electricity and Repealing Directive 2003/54/EC, vol. L211, no. August. 2009, p. L 211/55-L 211/93. 